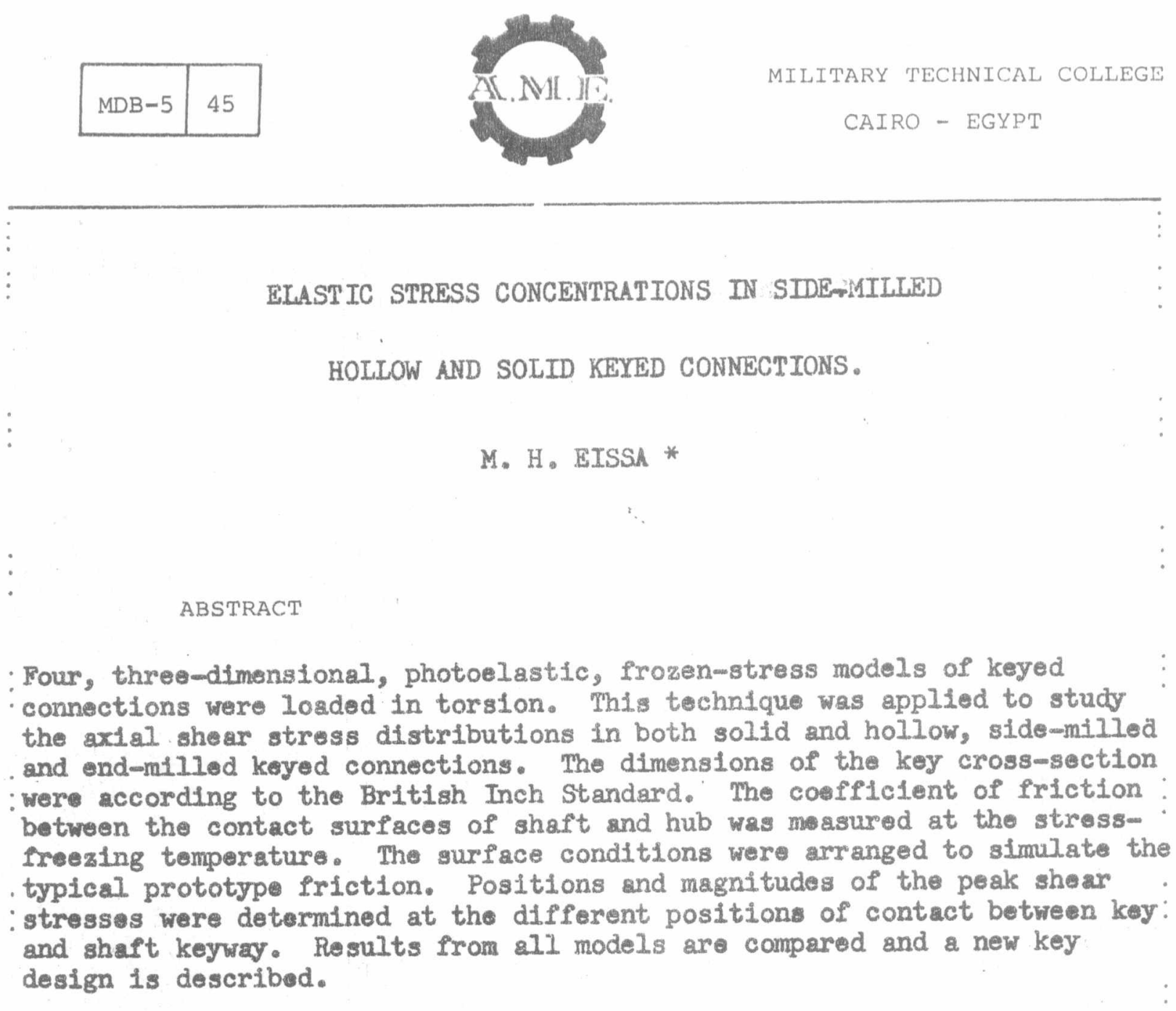

.

* Lecturer, Faculty of Electronic Engineering, Menoufia University, EGYPT. 
FIRST A.M.E. CONFERENCE

29-31 May 1984, Cairo

INTRODUCTION

The analysis of trosses $1 . n$ keyed connections started at the beginning of this century. Cough [1] carriad out tosts on mild stoel shaftg with wrought Iron koys. He reported that faliuro occurred at the ends of keys and k.yways and the final fotigue crack was always in clrcumferential. direction. He also found a series of cracks radiating from the shaft keyway 11litet, showing that the maximum stress concentration occurred thore.

Solakian and Karolitz [2] and Glbson and G1Let [3] moasured the stresses In keyed connectiong under torsion, using twomdinensional photoclastic models representing a transverse slice through the keyed assemblies. They observed high stresses at the positions of contact between keyway edges and the key and between the key chamfer and the keyway corners. Peterson [4]: observed that the stress field in a keyed connection is three-dimensional and can not bo analysed with twomdimensional problems.

: Okubo ot al [5] used the electroplating technique of strain analysis to measure the shear stresses at the ends of keys and keyway fillets under torsion. They reported that the stresses at the keyway fillet is reduced as the fillot size is increased.

Macdonald [6 to 9] measured the static torsional strength of kayed assembl. ims using difreront types of steel modis. He studied the shear stresses at the contact polnts between keys and keyways using the photoelastic sandwich technique. He compared the metric [10] and Inch [11] standards rectangular, paraliel keyed connections. He concluded that the inch connectfons are slightly better than the metric in static torsion and that the stresses are docreased as the key length 1.8 increased.

Orthwein [12813] applind threemdimensione], photoelastic, frozenmstress technique to determine the tensile stress near the rront ends of keys and kryways Ioaded in torsion. He also studied the offect of key and separation: from the keyway and of contact. He suggasted a new koyway and shape to reduce the stresses thero.

:Fissa and Fessler used twomimenglonsl lavestigations [14\&15] to study the - fects of torque magnitude, key width, key thickness, keyway fillet size, hub outside diameter, key chamfer shape, fit of key in shaft, fit of key in hub, fit of shaft in hub. and coefficient of friction between components on the lastic stressos in the prismatic part of keyed connoctions. They applied the photoelastic coating technique [16] to determine the plastica elastlc stress and strain distributions in different steel models. Thoy studied the effects of key length, position of torque reaction, keyway fillet size, imperfect keyway, keyway type and key end shape on the elastic :stress distribution using throe-dimenstonal, photoelastic models. They ostablished emperical equations which can predict the elastic stress concentration factors for any ky dimengion [17 to 21].

In the present work, four, three-dimensional, photoelastic. (Araldite), frozen-stress models are used to determine the elastic stress distribution along the key length at the contact lines between keys and keyways, in standard inch keyed connections loaded in torsion with typical coefficient iof friction. Solid and hollow, sido-milled and end-milled keyed connections 
are considered. Experimental resilts are compared with the predicted values from the mperlcal equations derived by the author before [19].

: SHAPES OF THE MODELS

Flg. 1 shows for both types of connections that the hub is as long as the sey. The key and keyway dimensions are the standard values for shaft diametor $d_{9}=4.0$ inch [11]. The inner shaft diameter ' $d_{1}$ is half the outer one $\mathrm{d}_{0}$. The main dimensions are:

$\begin{array}{ccc}\text { key width } & \text { key thickness } & \text { keyway rillet } \\ 0 & 0.198 \mathrm{~d}_{0} & 0.16 \mathrm{~d}_{0}\end{array}$

The torqu was applied to the hub through two diametricaliy opposite pins as shown in Figs. 1 \& 2 .

The lits between the components were:

$$
\begin{aligned}
& \text { a. Interference of key in shaft keyway } \\
& \text { b.ctranslition of ksy ir hub keyway } \\
& \text { c.transition of shait in hub }
\end{aligned}
$$

The minimum material conditlons were used during manufacturing the models : :to study the worst case of the connections. The measured coefficlent of Priction varied between 0.14 and 0.15 with silicone groased contact surfoces.

\section{EXPERTMENTAL WORK}

Models were machlned Prom castings of Araldite CT 200 with Hardener HT 907 " (mixture 100: 60: parts by welght). Shafts and hub bores were ground to surfaco finish CLA values between 2 and 4 m. The roundness was also :measured for all models; the maximum out-of - xoundiness was about 4 pm.

The keyway profile produced by the specially ground cutters were checked before the cuttors were used. Key sides were ground to ensure the correct:

Iits in keyways. Maximum parallelism arror between the keyway and the shart axis was about $15 \mu \mathrm{m}$.

The models were loaded in palss as shown in Flg. 2 with the middle of the keys in the same horlzontal plane as the shatt axis, Inmersed in dense, inert oll to minimise self-wolght affects. The torque was applied to the : hubs through the two diametrically opposite pins shown in Figs. 1 and 2. The hubs rested in Vee-blocks but the remainder of the front hub welght was counterbalanced to eliminate any frictional restraint thex as reported bs fore $[18]$.

After the stress-freezing cycle was applied, keys were glued to the shaft : (at the keyway free side) and siliced together perpendicular to the keyway surface. Mrin slices were $1.5 \mathrm{~mm}$ thick in the prismatic part and 1. Omm thick in the keyway onds. Sub-slices cut from the main slices, needed to determine the principal stress directions were $0.5 \mathrm{~mm}$ thick. 
ANALYSIS

All stresses were dotermined from photoslastic, normal. Incidence readings. ; Oblique incidence measurements would subject to large orrors due to large stress gradionts associated with tho mall fillet radil and contact conditions.

Nominal stresses were determined from slices cut at $45^{\circ}$ to the shaft axas in the plain, central parts. The calculated probable errors of stress lindex wers:

$$
\begin{aligned}
& \text { a. typical probable arror } 184 \% \\
& \text { b. greatest probable arror } 137.5 \%
\end{aligned}
$$

Comordinate directions were defined as shom in FIg. 1 and 3 . The contact stross perpendicular to the keyway surtace, fin the y direction was called: $O_{\mathrm{C}}^{-}$. It was always a principal stress along the key length. The stross least inclined to the $x$ drection $1 \mathrm{~s}$ approximately axial in the prismatic part was callea $\sigma_{a}$. The third principal stross ora called $\sigma_{t}$. All are : show In Flg. 3 for a point in the keyway ad.

The maximum shear stresses at a.l positions of contact were determined from the following two oquations [17]. By viowing the main slice and sub-slice normally we get:

$$
\begin{array}{ll}
\vdots & \text { If } \quad \sigma_{a}>\sigma_{t}>\sigma_{c} \\
& \sigma_{a}-\sigma_{c}=F\left(n_{x} / t_{x}+n_{y} / t_{y} \cos ^{2} \alpha\right) \\
& \text { If } \quad \sigma_{t}>\sigma_{a}>\sigma_{c} \\
& \sigma_{t}-\sigma_{c}=F\left(n_{x} / t_{x}+n_{y} / t_{y} \sin ^{2} \alpha\right)
\end{array}
$$

Where $F$ is the matextal fringe value. The rolstive values of the principal stresses were determined us1ng a wedge compensator. Bacause large stresses occur in keyed connections, the local maximum shear stress is a good indication of the severity of the stressing at a point.

\section{LESULTS AND DISCUSSION}

Large stresses only occur where the transmitted torque is concentrated due to the discontinuities of key and ksyway profil.s [18]. The greatest strosses were always in the surfaces of contact between key and keyways. Results are only presented for the thres contact lines between key and shaft kayway, 1.*. Sb, Ss, So and at key hub contact Iine Kh.

Figure -4 shows the stress distributions along the prismatic part and around the koyway ends as calculated from equations 182, 1.0. either $\frac{1}{2}\left(\sigma_{a}-\sigma_{c}\right)$ or $\frac{1}{2}\left(\sigma_{t}-\sigma_{c}\right)$.

: Common Features of Rosults From all Models

All contact stresses in most of the prismatlic parts of all models decrease : approximately Iinearly away from the keyway end. The maximum values are always at or near the front where most of the torque is transmitted [18]. i.. 
In the keyway ends the stresses are always minimua and increase to a max: in the prismatic part at the end of the side-milled connections and at the shaft botton So (in end-milled connections) or to \& maximum in the round. and and another maximum in the prismatic part at the other contact lines (Ss \& Se ) in end-milied connections only.

Tablo 1 shows the maximun values of I for the differmt positions of contact in both the prismatic part and the round end of shaft keyway and key for 277 models. Table 1 ghows the following common foatures:

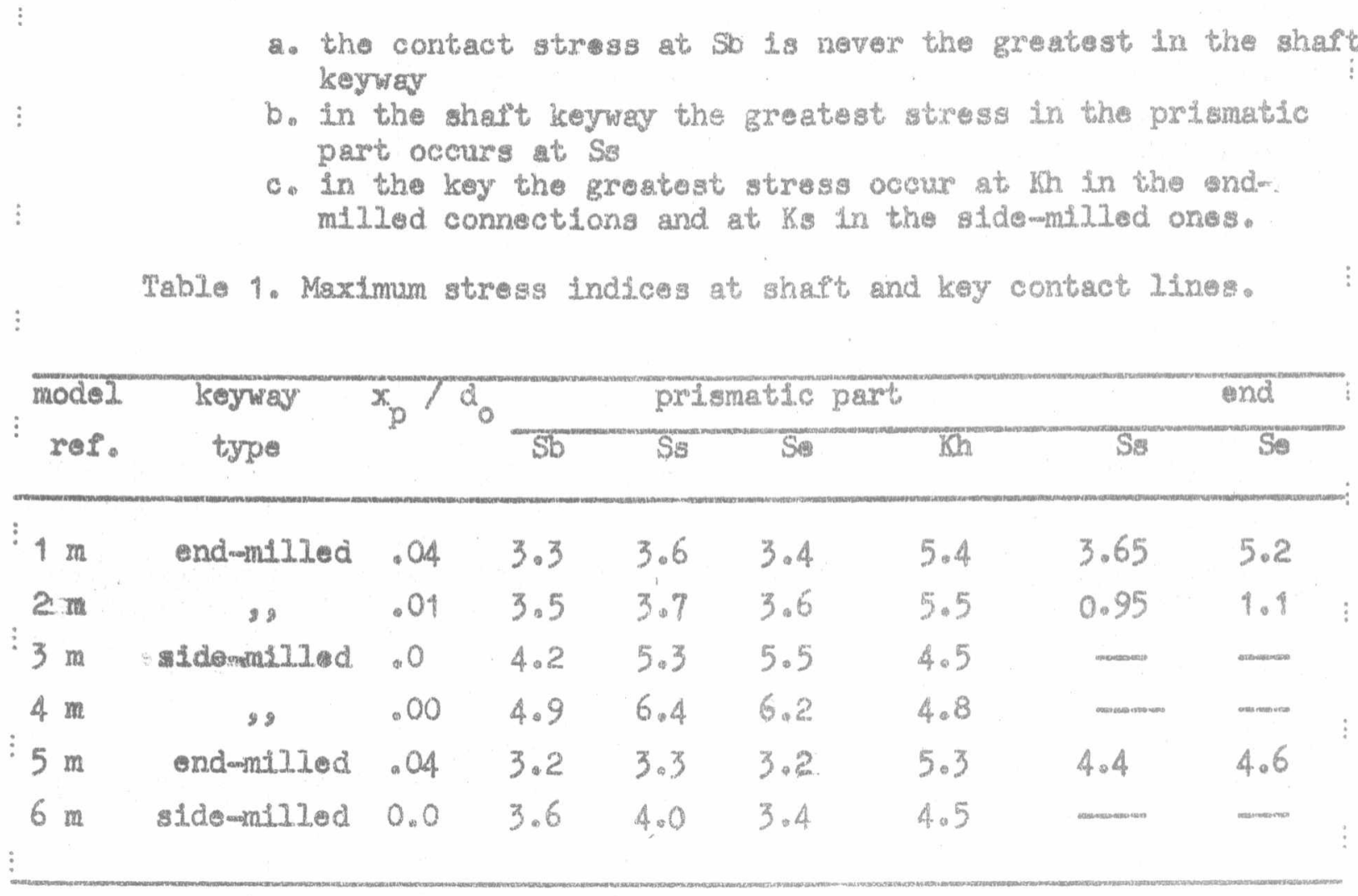

The followlng should be noticed in Table 1:

1. model $4 \mathrm{~m}$ has a hollow shaft with $\mathrm{d}_{1}=\mathrm{d}_{0}$

2. a.1. coefficients of friction were 0.15

3. naximan stress at $\mathrm{Kh}$ for model 2 m occurs at $x_{p} / d_{0}=m_{0} 02$ :

4. key of model. $2 \mathrm{~m}$ is chamfered and rounded, while that of model $6 \mathrm{~m}$ is rounded.

5. results of model $5 \mathrm{~m}$ are predicted from the equations derived by the author before [19].

6. nodel $6 \mathrm{~m}$ is suggested by the author to reduce contact stresses at the front of the connection. 
Comparison Between End-milled and S1dewnilled Connectons

From FIgure 4. At can be seen that in most of the prismatic parts of both

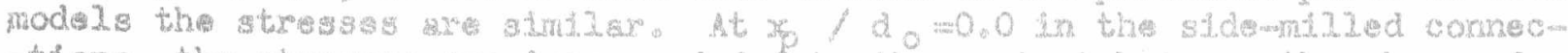
-tions. the stresses are Incxesasad due to the contact botwen the share edges

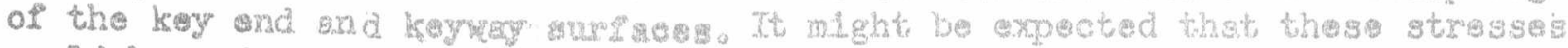

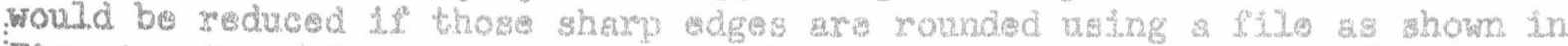
FIg. 1. Compax'son betwean the results of the suggested model. "6 m" and

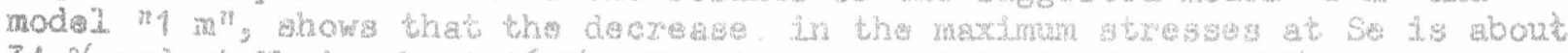

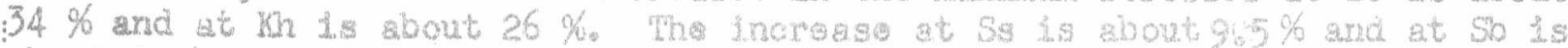

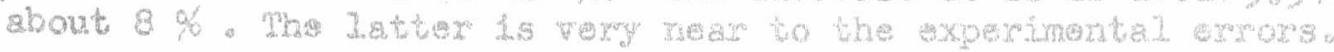

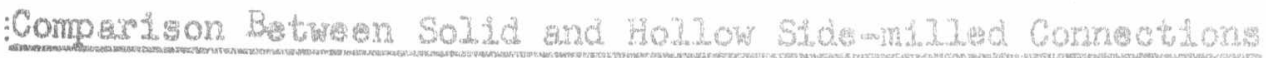

Comparison between modely 3 m \& 4 mis given below:

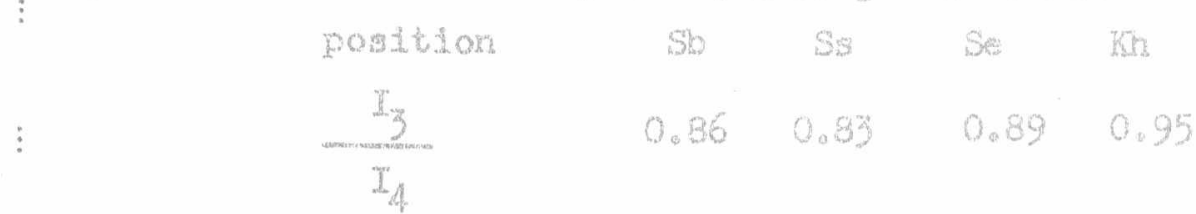

It is clear that the stresses at contact Ifneg in the sheft are will. affecm

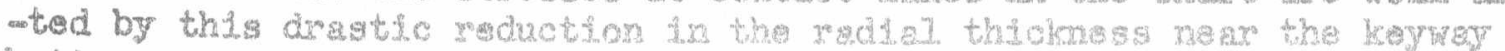

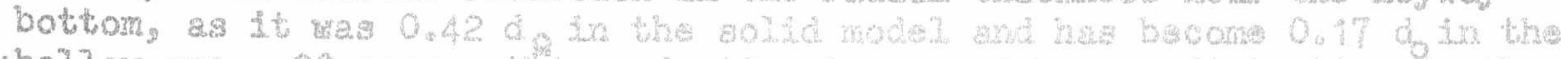

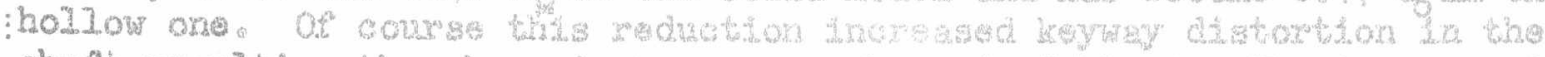

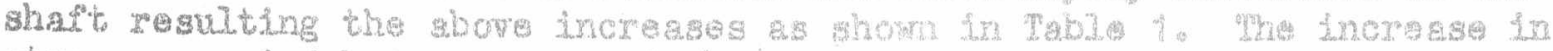

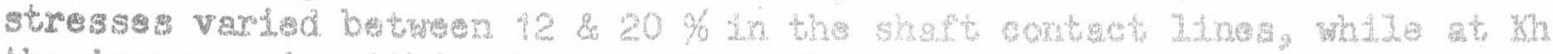

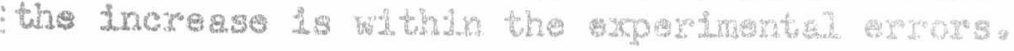

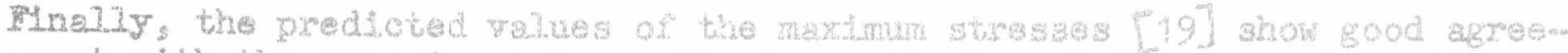

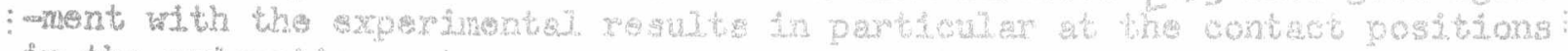
in the prosisatio parto

\section{CONCLUSTONS}

Stros distributions an keyed ennections exe wery conshioated due to the

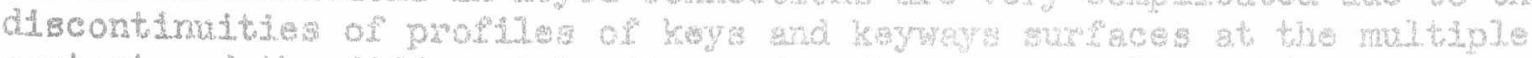
contact and the difirnent loadung moder thoy are usuraly subject to.

The followlng can be concludad:

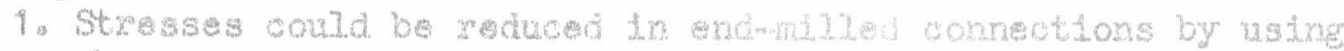
chanfered and rounded key ends.

2. Strosses in sidemilled comnections could be reduced 3 f rounded key sinds are used.

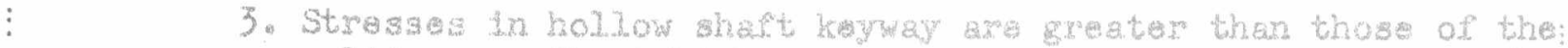
sclld oxe. It might bo axpected that ahaft with di $=\mathrm{d}_{0} / 4$, will. not affect tho local stresses at the shaft contact lines.

4. A chamfered and rounded end milled heyed connection is the optimum cornection as it has the lowest stress concentrations and the maller keyway length compsred to the suggasted siden. milled connections. 
\begin{tabular}{|l|l|}
\hline $\mathrm{MDB}-5$ & 51 \\
\hline
\end{tabular}

FIRST A.M.E. CONFERENCE

29-31 May 1984, Cairo

\section{ACKNOWLEDGEMENTS}

The author would Ilko to thank the NOTRINGHAM UMIVERSTY technicians for their skilled assistance in casting and glicing the models and the Depart-ment of Mechanleal Englneorling for providing the necessary facilition.

\section{REFERENCES}

1. Gough, H.J. "The affect of Keyways Upon the Stiffinoss of Shafts Subjected to Torsional Strasses" Aexon. Research Councll, Tech. Report $488(1925)$.

2. Solakian, A,G. and Kareliti, G,B. "Fhotoclastic Study of Sharing :

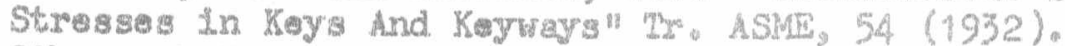

3. G1bson. W.H.H. and Gllet, P.Mo in Tramission of Torque by Keys And Keyways" Ix. Instn. Fong, Austral1. 10 (1938).

4. Paterson, R.E. "Fatdgus of Shutts Haring Keyways" Proc. ASTM, 32 (21), (1932).

5. Okubo, H. Hosono, $\mathrm{K}$. and Sakak1, $\mathrm{K}_{\mathrm{N}} \mathrm{H}$ The Stress Concontration in : Keyways When Torque Ls Transmitted Tharough Keyg "Exp. Mech., 8(1968).

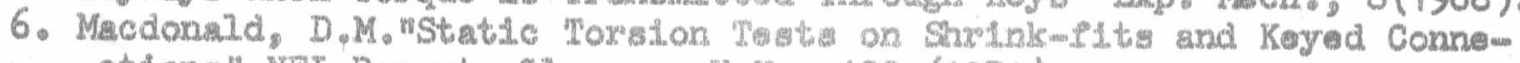
-ctions" NEL Report, Clakgow, U.K. 489 (1971).

: 7. Macdonald, D.M. "Comparison of Theh And Matric Keys in static Torsion" MEL Report, GLasgow, U.K. .526 (1972).

8. Macdonald, D.M." Loaded. Key RosctLon And Stxesses" NEL Beport, Gissgow, U.K. 606 (1976).

9. Macdonald, D.M. "Key Length And It \& EPrset on The Static Toxsional Strength of Koyad Jolnts in MLI Report, GIasgow, U.K., 635 (1977). :

10. British Standard Institution: Metric Kergs and Keyways BS 4235, Part I (1967). 11. Bxitish Standard Institution: Tnch Koys And Koyways. BS 46, Part I,
(1958).

12. Orthwoin, W.C. "Imyway Strosses When Torolonal Loading is Applied by The Keys Exp. Heh. 15 (1975).

13. Ortbwein, W.C." A Wew Key And Keyway Degagn Trans. ASME, J Mech. Design, 101 (1979).

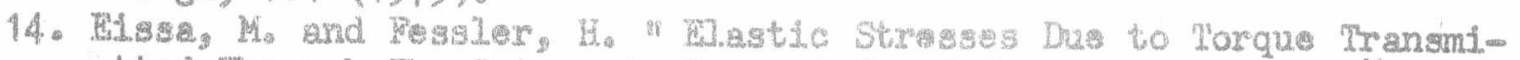
antod Through The Prosmatlic Part of Kayed Conzactlong" Part I

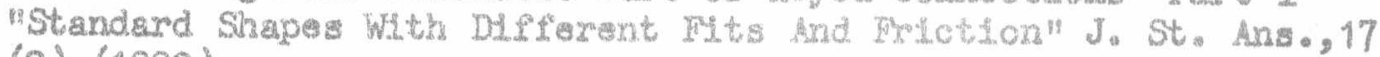
(2), (1982).

15. Flss, M. and Fesslar, H. MElastic Strasses Du to Torque Wransmitted. Through The Rismatic Part of Keysd Conmectiong" Part II, inf fect of Shape With Usuel Fits And Friction" y. Sta Ans.g 17(4), (1982).

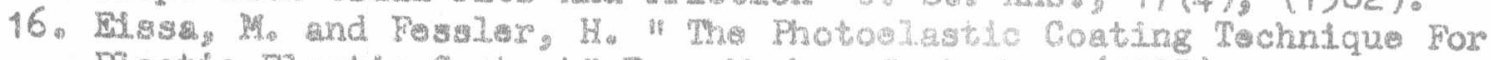
PiastiemELat10 Contret" Axp. Msch., Septenber (1983).

17. EJ.38s, M. and Fossler, H. Wheduction of glastio Stress Concentration in and-milled. Keyred Connections" SESA Spling Keoting, Dearborn, (1981).

18. Efssa, M. and Fossier, H. "DLstribution of Transmited Torque And : Elastic Stresses in Keyod Connections" 7 th Intr. Confo Exp. Str. Ans, Ha1fo, Israel, Aug $(1982)$.

: 19. Elssa, M. "Elastic Stress Dsstribution lis Solid and Hollow End-milled Keyod Shartis" PEDAC, ALEXANDRIA, Dec. (1983).

20. Ej.ssa, M. and Fessler, H." Three-Dinenatonal Elastic Stress Distrib-ution in End-milled Keyed Connections" J.Str. Ans., 18 (2), (1983).

21. Efss9., M. and Fessler, H." Photoelastlc Stross Distributions in End-

L.. milled And Side-milled Keyed Connections Under Torsion" AMSE (1983) 


\section{NOTATION}

Dimensions and positions of contact are definod in Fig. 1.

$n_{x}, n_{y}$

$t_{x,}, t_{y}$

$x_{p}$

$\mathrm{X}_{2}, \mathrm{Y}_{2}, \mathrm{z}, \emptyset$

$\sigma_{c}, \sigma_{t}, \sigma_{a}$ stress index, $(\mathrm{n} / \mathrm{t}) /\left(\mathrm{n}_{\text {nom }} / \mathrm{t}_{\text {nom }}\right)$.

fringe orders in $x$ and $y$ directions

slice thicknesses defined in Fig. 3.

position in prismatic part (see FIg. 1.)

co-ordinat directions defined in Fig. 3. principal strossas as showa in Fig. 3 .
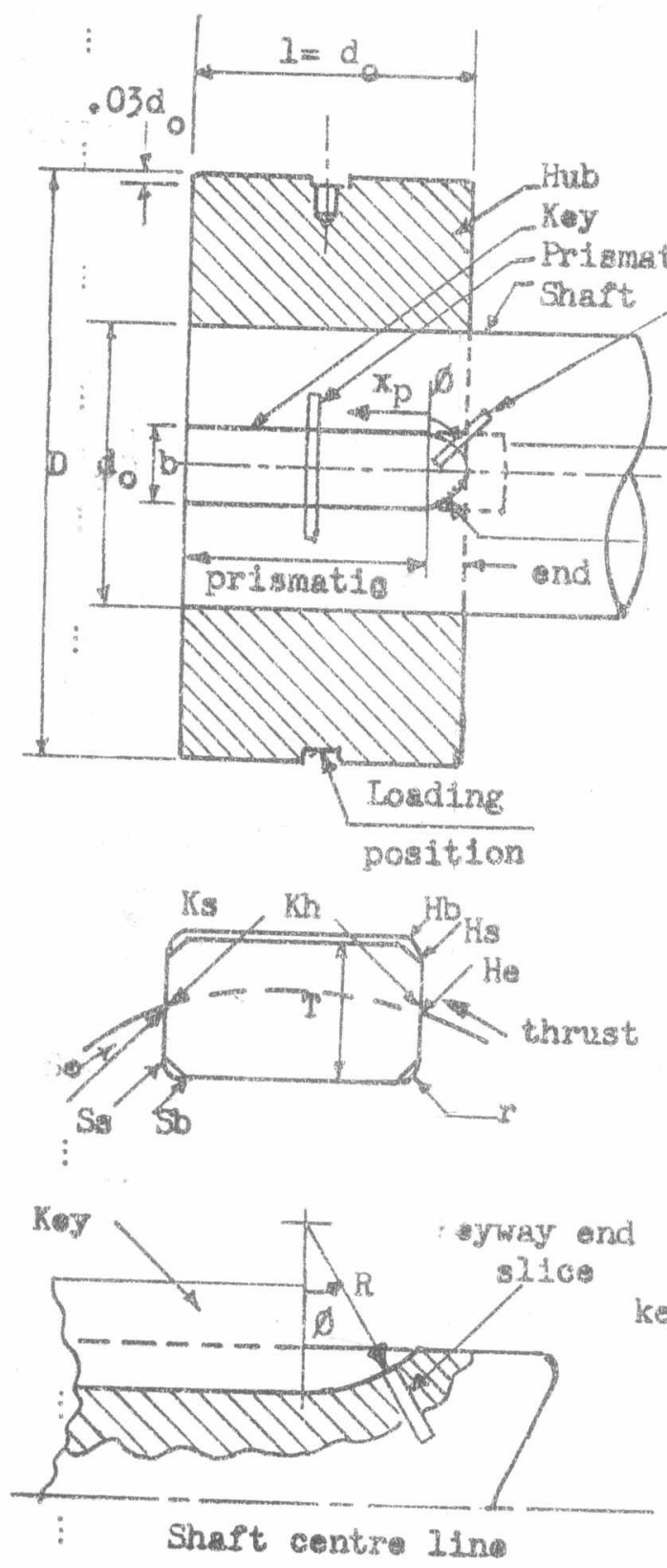

Tape fixad to
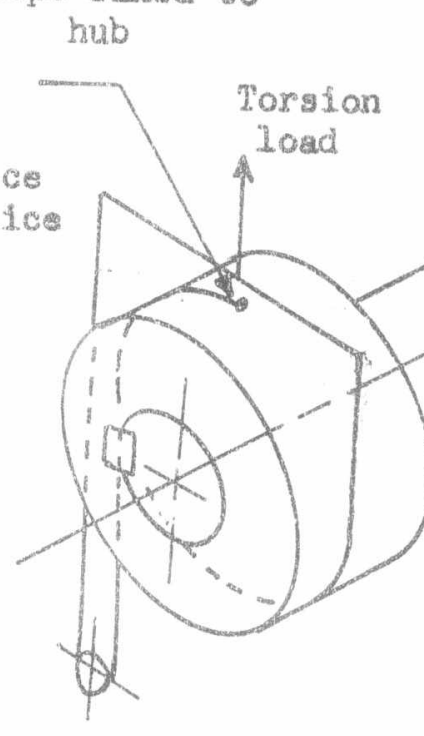

Mar
kry
ard

Find s11\%

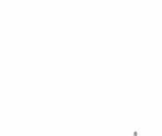

Emptis keyway

Fig. 1. Mrdel dimensions. L.. 


\begin{tabular}{|l|l|}
\hline MDB-5 & 53 \\
\hline
\end{tabular}

FIRST A.M.E. CONFERENCE 29-31 May 1984, Cairo

6
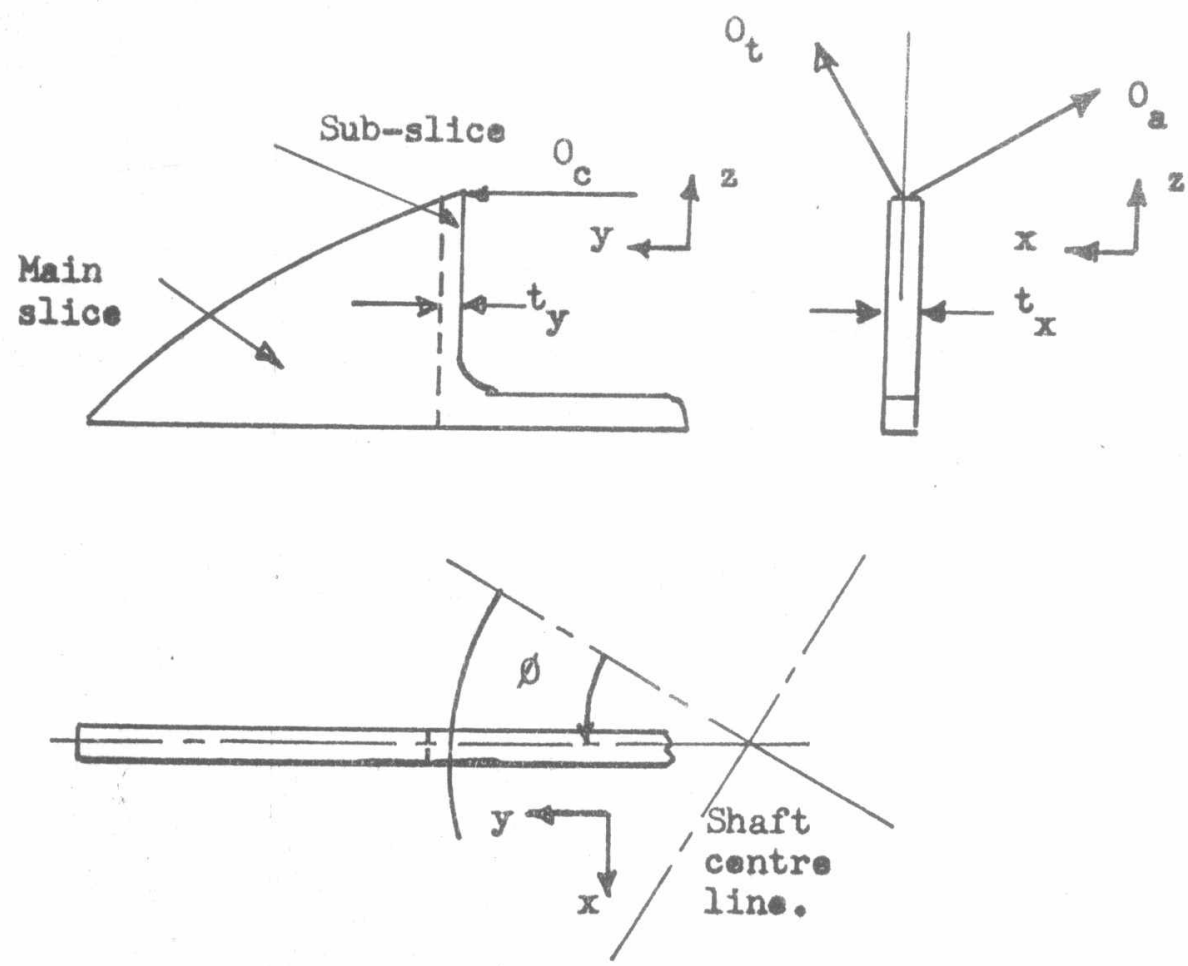

FIg. 3. Co-ordinates and directions of the principal stresses at a point in the keyway ond.

Models

$\therefore \quad+1 \mathrm{~m}$. $3 \mathrm{~m} 04 \mathrm{~m}$

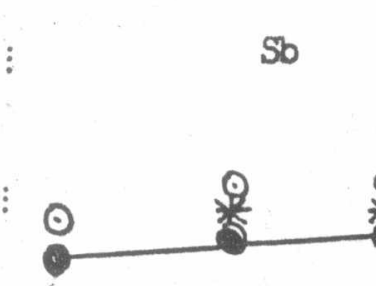

(8)

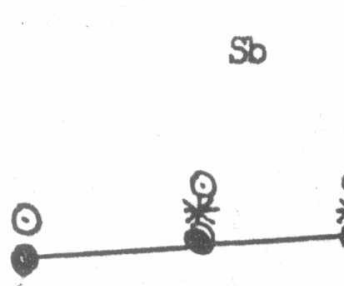

Sb

$\vdots$

1.0

0.8

0.6

0.4

$x_{p} / d$

(a).

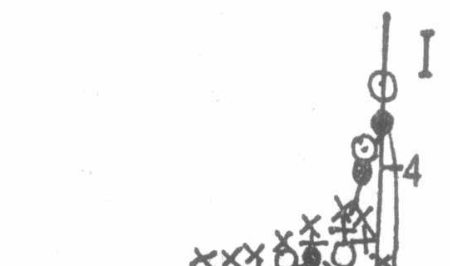




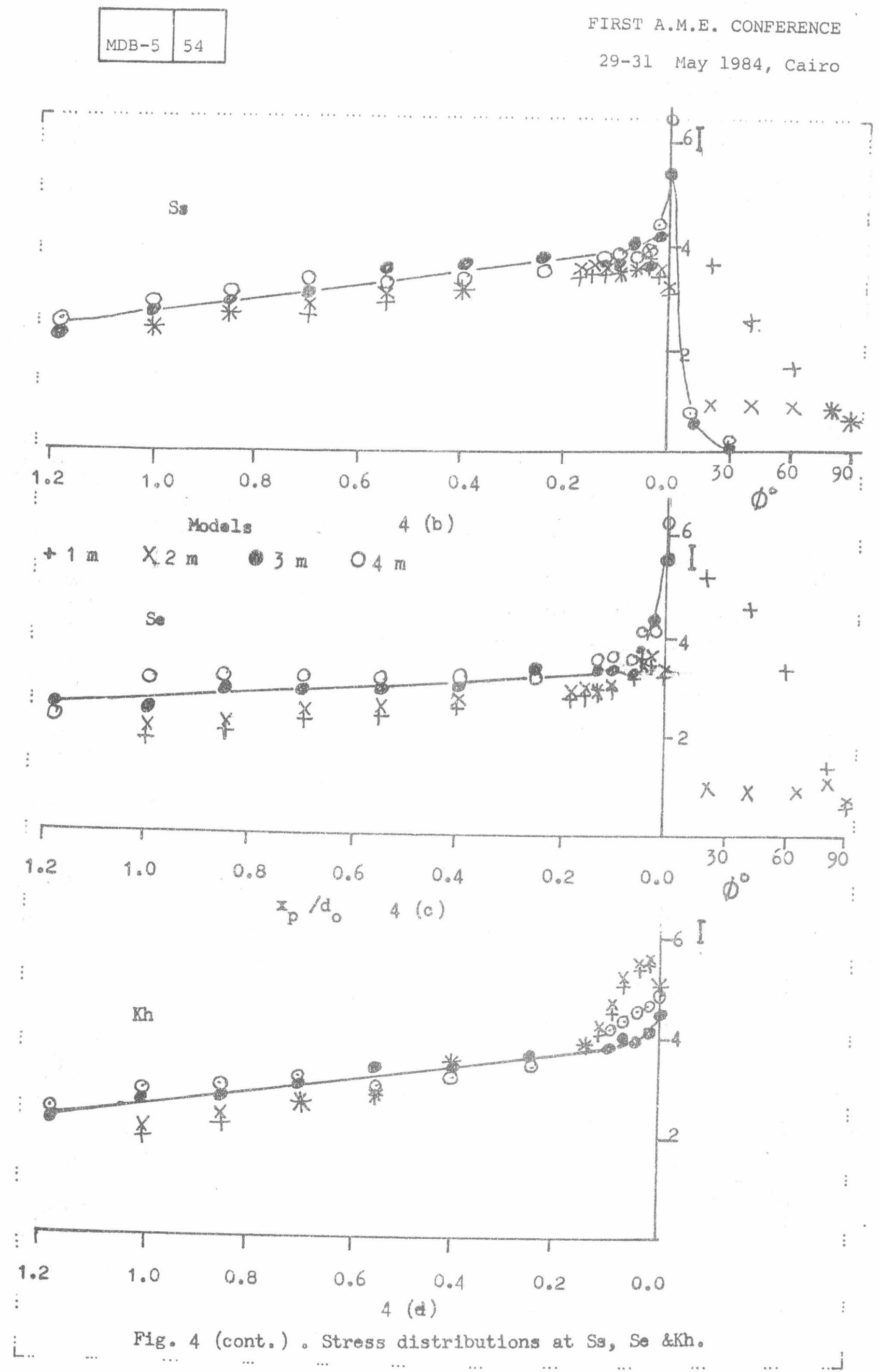

